\title{
Securitización e inversiones extranjeras: control del riesgo de ciertas inversiones para la seguridad nacional del Estado*
}

Fecha de recepción: 11 de febrero de 2018

Fecha de aceptación: 14 de junio de 2018

Doi: dx.doi.org/10.12804/revistas.urosario.edu.co/acdi/a.6528

\section{Carlos Esplugues Mota**}

Resumen: el aumento constante de las inversiones extranjeras durante las últimas décadas ha venido acompañado de un cambio en sus parámetros. El origen de las inversiones varía, como lo hace su naturaleza y destino. La posibilidad de que sectores clave de la economía del Estado receptor acaben en manos de inversores extranjeros, en ocasiones pertenecientes o controlados por un Estado extranjero, es vista con prevención en muchos países y acentúa la creciente oposición al libre comercio y a la inversión extranjera. La limitada respuesta —expost— ofrecida por el marco normativo internacional lleva a los Estados a diseñar respuestas ex ante, dirigidas a controlar ciertas inversiones que por su origen, condición o destino pueden resultar potencialmente riesgosas para su seguridad nacional.

* El artículo presentado se ha elaborado en el marco del Proyecto I+D Mineco DER201674945-R y del Proyecto Prometeo GVA-2018/111.

** Catedrático de Derecho Internacional Privado y Comercio Internacional, Universidad de Valencia (España); árbitro y mediador internacional; representante de España en el WG II Resolución de Litigios de Uncitral; y antiguo presidente de la Asociación Española de Profesores de Derecho Internacional y Relaciones Internacionales. Correo electrónico: carlos.esplugues@uv.es, ORCID: https://orcid.org/0000-0001-8568-5296

Para citar este artículo: Esplugues Mota, C., "Securitización e inversiones extranjeras: control del riesgo de ciertas inversiones para la seguridad nacional del Estado", Anuario Colombiano de Derecho Internacional (ACDI), 2019, 12, pp. 121-156. Doi: dx.doi.org/10.12804/revistas.urosario.edu.co/acdi/a.6528 
Palabras clave: inversiones extranjeras directas, seguridad nacional, securitización, control de inversiones extranjeras, mecanismos de evaluación de inversiones extranjeras.

\title{
Securitization and Foreign Investment: Evaluation of FDI on National Security Grounds
}

\begin{abstract}
Foreign investment has increased steadily during the last decades. This fact has come accompanied by a change in some of its basic traits: its origin, its nature or its destination have also varied overtime. Today, when free trade and foreign investment are increasingly subject to criticisms in many places, the possibility for key sectors of the economy of the state to be controlled or owned by foreign investors, in many cases sovereign investors, is approached with prevention in many countries of the world. The limited —expost — response provided by the international legal framework on investment forces states to explore new instruments to control foreign investment proposals that may endanger their national security due to its origin, nature or destination, among others.
\end{abstract}

Keywords: Foreign direct investment, national security, securitization, control of foreign direct investment, screening systems of evaluation of foreign investment.

Securitização e investimentos estrangeiros: controle do risco de certos investimentos para a segurança nacional do Estado

Resumo: o aumento constante dos investimentos estrangeiros durante as últimas décadas tem vindo acompanhado de uma mudança em seus parâmetros. A origem dos investimentos varia, como também o faz sua natureza e destino. A possibilidade de que setores chave da economia do Estado receptor acabem em mãos de investidores estrangeiros, em ocasiões pertencentes ou controlados por um Estado estrangeiro, é vista com prevenção em muitos países e acentua a crescente oposição ao livre comércio e ao investimento estrangeiro. A limitada resposta —ex postoferecida pelo marco normativo internacional leva aos Estados a desenhar respostas ex ante, dirigidas a controlar certos investimentos que por sua 
origem, condição ou destino podem resultar potencialmente riscosas para sua segurança nacional.

Palavras-chave: investimentos estrangeiros diretos, segurança nacional, securitização, controle de investimentos estrangeiros, mecanismos de avaliação de investimentos estrangeiros.

\section{Introducción}

El régimen jurídico de las inversiones extranjeras viene históricamente caracterizado por su condición desestructurada y asistemática. Los potenciales problemas derivados de la coexistencia de una amplia pluralidad de normas de distinta naturaleza y procedencia han quedado mitigados por la amplia aceptación, durante las últimas décadas, del paradigma de la bondad del libre comercio y de la libre circulación de inversiones. Esta situación, empero, está cambiando aceleradamente. Las alteraciones que han acompañado al incremento constante de los flujos inversores de los últimos años — cambios en el origen, naturaleza o destino de la inversión, por ejemplo_- unidas a la profunda crisis económica que han padecido distintos Estados desde 2007, están conduciendo a poner este paradigma en duda y, a partir de ello, a someter a presión a todo el modelo normativo internacional en materia de inversiones. Atribuyéndole, por ende, unos objetivos y funciones de los que históricamente ha carecido.

Un número creciente de Estados — desarrollados y menos desarrollados — ven con aprensión la posibilidad de que industrias o sectores estratégicos de su economía caigan bajo el control de inversores extranjeros provenientes — ahora, en muchas ocasiones - de economías emergentes, o controlados por gobiernos foráneos. Ello se traduce en la consolidación de una atmósfera menos positiva para las inversiones extranjeras en muchos lugares, y en la correlativa exploración por parte del Estado de las posibilidades de controlar, y en su caso limitar, ciertas inversiones foráneas con base en criterios no necesariamente económicos.

En una primera fase, esta voluntad de control se ha focalizado en el momento posterior al desarrollo de la inversión y ha estado, por ello, directamente vinculada al entramado convencional existente en este sector. Sin embargo, las limitaciones consustanciales a esta respuesta a posteriori están llevando a los Estados a explorar, de manera cada vez más habitual, 
otras vías de control previas al desarrollo de la inversión. Algunas de ellas, ya existentes de forma tradicional, y otras novedosas.

Este cambio de perspectiva trasciende la mera opción metodológica, al aparecer directamente vinculada a la protección de la seguridad nacional, de los intereses esenciales de seguridad, o nociones similares, del Estado receptor de la inversión. Con lo que el derecho de las inversiones extranjeras se ve dotado de una dimensión de seguridad de la que históricamente ha carecido, cuyo significado no siempre es claro y para la que, además, no necesariamente está preparado.

El presente trabajo analiza esta nueva realidad generada, y explora algunas de las respuestas que se están gestando en el plano comparado. A partir del análisis de la realidad de la inversión extranjera y de su régimen jurídico en el momento actual, se procede a resaltar los cambios de percepción que de manera acelerada les acompañan, y la consiguiente consolidación de un discurso de securitización inexistente hasta fechas recientes en este sector.

El texto tiene como objetivo examinar las complejidades inherentes al control de las inversiones extranjeras en el momento actual, contribuyendo a explicitar un debate que de forma creciente se está planteando en la doctrina de algunos países. Se busca resaltar el cambio de foco y de discurso, a la vez que la insuficiencia del marco normativo internacional, para ofrecer una respuesta global a un problema global, y el recurso, de nuevo, a soluciones estrictamente nacionales, dejando abierta la incógnita de la incidencia que la consolidación de este movimiento puede tener para la libre circulación de inversiones en un futuro mediato.

\section{Una historia de éxito carente de un reflejo normativo e institucional}

Los flujos de inversión extranjera directa han crecido de forma constante desde finales de la década de los ochenta del siglo pasado hasta nuestros días. Los US $\$ 50$ billones alcanzados a comienzos de 1980 se multiplicaron por cuatro en los diez años siguientes, saltando hasta los US $\$ 200$ billones de 1990. Y llegaron hasta la cifra de US\$1,75 trillones de inversiones extranjeras en $2016 .^{1}$

UNCTAD, World investment report 2015. Reforming international investment governance, Naciones Unidas, Nueva York-Ginebra, 2015, p. 25; UNCTAD, World investment report 2017. Investment and the digital economy, Naciones Unidas, Nueva York-Ginebra, 2017, pp. vii y x. 
Este incremento sin parangón se ha visto favorecido por la conjunción de una pluralidad de factores de índole diversa. Así, a los avances derivados de la revolución tecnológica, de la existencia de procesos de desregulación desarrollados en muchos Estados o de la liberalización del comercio internacional, ${ }^{2}$ se han sumado las positivas condiciones económicas, el diseño de marcos regulatorios favorables a la inversión foránea o la presencia de políticas estatales de promoción de estas en gran parte de los países. ${ }^{3}$ Todo ello en un entorno de aceptación mayoritaria de los beneficios generados por la inversión extranjera. ${ }^{4}$

Significativamente, sin embargo, este incremento incesante de los flujos inversores no ha venido acompañado del desarrollo de una regulación global para las inversiones extranjeras en línea con la existente para el comercio internacional. Ni, tampoco, del establecimiento de una estructura institucional para las inversiones, equivalente a lo que supone la OMC para aquel. ${ }^{5}$ En este sentido, el propio Tribunal Internacional de Justicia manifestaba en 1970, en su sentencia del 5 de febrero en el asunto Barcelona Traction, Light and Power Company, cuán sorprendente resultaba que a pesar del crecimiento "[...] of foreign investments and the expansion of the international activities of corporations, in particular of holding companies, which are often multinational, and considering the way in which the economic interests of States have proliferated, [...] the evolution of law has not gone further and that no generally accepted rules in the matter have crystallized on the international plane". ${ }^{6}$

2 Bitzenis, Aristidis, "Globalization and foreign direct investment", en Bitzenis, Aristidis, Vlachos, Vasileios A. \& Papadimitriou, Pyrros (eds.), Mergers and acquisitions as the pillar of foreign direct investment, Palgrave McMillan, Nueva York, 2012, p. 10.

3 Una evaluación del número de medidas legislativas favorables o menos favorables a las inversiones extranjeras se encuentra en UNCTAD, World investment report $2015 \ldots$... op. cit., p. 102; y UNCTAD, World investment report 2017..., op. cit., p. xi. Con relación a las medidas de promoción de la inversión, ver Economou, Persephone \& Sauvant, Karl P., "Recent trends and issues in foreign direct investment 2010", Yearbook on International Investment Law \& Policy, 2010-2011, p. 31.

4 Thomsen, Stephen \& Mistura, Fernando, Is investment protectionism on the rise? Evidence from the OECD FDI Regulatory Restrictiveness Index' $O E C D$ global forum on international investment, OCDE, París, 2017, p. 2.

5 Broude, Tomer, "Investment and trade: the 'Lottie and Lisa' of international economic law?", en Echandi, Roberto \& Sauvé, Pierre, Prospects in international investment law and policy World Trade Forum, cup, Cambridge, 2013, pp. 142-143.

6 Barcelona Traction, Light and Power Company, Limited (Belgium v. Spain), [1970] ICJ 1, pp. 47-48, par. 89 . 
Así, y tras el fracaso de los diversos intentos de establecer un régimen jurídico internacional organizado y omnicomprensivo, ${ }^{7}$ el marco normativo internacional de las inversiones extranjeras se caracteriza, todavía hoy, por su carácter fragmentado y desestructurado, y por la pluralidad de sus fuentes. ${ }^{8}$ En él se combinan un conjunto limitado de soluciones multilaterales, fundamentalmente vinculadas a las escasas normas sobre inversiones recogidas en el entramado jurídico sobre el que se articula la OMC, ${ }^{9}$ con una respuesta fundamentalmente bilateral ${ }^{10}$ —a fecha de 2017 se habla de 3324 APRI, ${ }^{11}$ de diferente origen, naturaleza, ámbito y partes involucradas - ${ }^{12}$ que tiende habitualmente a reflejar los intereses de los países desarrollados, como tradicionales exportadores de capital, y de sus actores, estableciendo elevados estándares de protección para estos. ${ }^{13}$

A ello se suman ciertas normas convencionales de ámbito regional. Algunas escasas, pero relevantes, reglas de derecho internacional consuetudinario en relación con la protección de los derechos de los extranjeros, y diversos principios generales del derecho internacional; ${ }^{14}$ así como el

Sauvé, Pierre, "Multilateral rules on investment: is forward movement possible?", Journal of International Economic Law, 2006, 9, (2), pp. 328-340; Geiger, Rainer, "Towards a multilateral agreement on investment", Cornell International Law Journal, 1998, 31, pp. 467 y ss., especialmente 469-475.

8 Lorz, Ralph Alexander, "Fragmentation, consolidation and the future relationship between international investment law and general international law", en Baetens, Freya (ed.), Investment law within international law. Integrationist perspectives, CuP, Cambridge, 2013, pp. 483-484; Pauwelyn, Joost, "Rational design or accidental evolution? The emergence of international investment law", en Douglas, Zachary, Pauwelyn, Joost \& Viñuales, Jorge E. (eds.), The foundations of international investment law bringing theory into practice, OUP, Oxford, 2014, pp. 14-18.

9 Steger, Debra P., "International trade and investment: towards a common regime?", en Echandi \& Sauvé, Prospects in international investment law..., op. cit., pp. 160 y ss.

10 Vandevelde, Kenneth J., "A brief history of international investment agreements", en Sauvant, Karl P. \& Sachs, Lisa E., The effect of treaties on foreign direct investment: bilateral investment treaties, double taxation treaties, and investment flows, OUP, Oxford, 2009, p. 39.

11 UNCTAD, World investment report $2017 \ldots$... op. cit., p. xii.

12 Steger, "International trade and investment...", op. cit., p. 157.

13 Sauvant, Karl P., "The regulatory framework for investment: where are we headed?", en Ramamurti, R. \& Nashai, N. (eds.), The future of foreign direct investment and the multinational enterprise, Emerald Books, Research in Global Strategic Management, Vol. 15, Bingley, 2011, p. 413.

14 Kläger, Roland, Fair and equitable treatment' in international investment law, CUP, Cam- 
elenco de decisiones judiciales arbitrales existente en la materia, ${ }^{15} \mathrm{y}$ distintos instrumentos de soft law. ${ }^{16} \mathrm{Y}$ todo ello coexiste, a su vez, con el marco normativo fijado por cada Estado en este sector, destinado generalmente a crear una atmósfera favorable para la atracción de inversiones extranjeras. ${ }^{17}$

\section{La consolidación de un cambio de perspectiva en relación con las inversiones extranjeras}

\subsection{El cambio de paisaje}

El entramado normativo apuntado dibuja un entorno regulatorio diseñado mayoritariamente por los países exportadores de capital. Un marco jurídico que, hoy, sin embargo, parece encontrarse en una aguda fase de transición, influido por ciertos cambios de calado que inciden en la realidad de las inversiones extranjeras en el plano global y afectan, en última instancia, a su regulación. ${ }^{18}$

En este sentido, el aumento constante de los flujos de inversión mundiales durante las últimas décadas ha venido acompañado de una alteración de algunos de sus parámetros tradicionales: ${ }^{19}$

bridge 2011, pp. 18-20 y 265-270; y Juillard, Patrick, "L'evolution des sources du droit des investissements", Recueil des Cours, 1994, (1), pp. 76-82. Ver también el laudo del 11 de octubre de 2002, en el asunto Mondev International Ltd. v. United States of America, ICSID Case ARB(AF)/99/2, pp. 41-42, pars. 120 y 121, en http://www.italaw.com/cases/documents $/ 716$, consulta del $1^{\circ}$ de febrero de 2018 .

15 De Brabandere, Eric, "Arbitral decisions as a source of international investment law", en Gazzini, Tarcisio \& De Brabandere, Eric (eds.), International investment law. The sources of rights and obligations, Martinus Nijhoff Publishers, Leiden-Boston, 2012, pp. 6 y ss. Nótese, igualmente, el laudo en el asunto $A W G$ Group Ltd. v. The Argentine Republic, Uncitral, Decision on liability del 30 de julio de 2010, p. 73, par. 189, en http://www.italaw.com/sites/default/ files/case-documents/ita0055.pdf, consulta del 2 de febrero de 2018.

16 OCDE, Freedom of investment, national security and 'strategic' industries. Progress report by the OECD Investment Committee, OCDE, París, 2008, p. 2.

17 Sauvant, “The regulatory framework...", op. cit., p. 411.

18 Muchlinski, Peter T., "Towards a coherent international investment system: key issues in the reform of international investment law", en Echandi \& Sauvé, Prospects in international investment law..., op. cit., pp. 411-413.

19 Esplugues, Carlos, Foreign investment, strategic assets and national security, Intersentia, Cambridge, 2018, pp. 6-22. 
1) En primer lugar, el origen de las inversiones extranjeras se ha modificado profundamente en todos estos años. La tradicional distinción entre países emisores de flujos de capital —los más desarrollados - y los receptores de estos - los emergentes o menos desarrollados - se ha visto difuminada. Algunas economías emergentes siguen siendo receptoras de capital extranjero a la vez que, sin embargo, actúan como relevantes exportadores de capital y juegan un papel destacado en el campo de las inversiones extranjeras. El supuesto de la República Popular China es muy relevante al respecto: en 2016 ocupó el tercer lugar como país receptor de inversiones con US $\$ 139$ millardos, ${ }^{20}$ a la vez que se encontraba en el segundo lugar como emisor mundial de flujos de inversión. ${ }^{21}$

2) Junto a ello, en segundo lugar, los sectores a los que se dirige la inversión internacional se han visto igualmente alterados. En la década de los setenta del siglo pasado, la inversión en servicios no alcanzaba el $25 \%$ de los flujos globales, mientras que tres décadas más tarde constituye cerca de dos tercios del total de inversión extranjera directa. Con un notable incremento de la inversión dirigida a sectores clave, como energía o telecomunicaciones. $^{22}$

3) A estos dos datos se ha unido, entre otros factores adicionales, un cambio relevante en la naturaleza del inversor. El crecimiento de los flujos inversores de los últimos tiempos está íntimamente ligado a la expansión de las llamadas sociedades multinacionales, el instrumento a través del que se canalizan la mayoría de ellos: ${ }^{23}$

20 El segundo, si lo unimos a Hong Kong —US\$92 billones—. Ver UNCTAD, "Global FDI flows slip in 2016. Modest recovery expected in 2017”, Global Investment Trends Monitor, 2017, 25, p. 3.

21 Con un total de US $\$ 383$ billones. Ver UNCTAD, World investment report $2017 \ldots$, op. cit., p. viii.

22 Sauvant, Karl P., Mascheck, Wolfgang A. \& McAllister, Geraldine, "Foreign direct investment by emerging market multinational enterprise the impact of the financial crisis and recession, and challenges ahead", en Sauvant, Karl P., McAllister, Geraldine \& Macheck, Wolfgang A., Foreign direct investments from emerging markets. The challenges abead, Palgrave Macmillan us, Nueva York, 2010, p. 5.

23 Páez, Laura, Liberalizing financial services and foreign direct investment. Developing a framework for commercial banking FDI, Palgrave McMillan, Nueva York, 2011, p. 30. 
hoy en día son más de 80000 , con una cifra superior a las 800000 filiales en todo el planeta. ${ }^{24}$ De estas sociedades, un número escasamente relevante en términos absolutos pertenecen o son controladas por el Estado: hablamos de unas 1500 sociedades —menos del 2\% del total— que poseen más de 86000 filiales - sobre un $10 \%$ del global de aquellas - ${ }^{25}$ y que, sin embargo, adquieren un creciente protagonismo en la actividad inversora mundial desde el inicio de la crisis financiera en 2007.

Más de la mitad de estas 1500 empresas estatales se encuentran localizadas en economías emergentes o menos desarrolladas, siendo China el país que cuenta con un mayor número de ellas. ${ }^{26}$ De hecho, las doce empresas chinas más importantes son estatales, ${ }^{27}$ como igualmente lo son más de la mitad de las empresas chinas presentes en el 2012 Fortune Global 500. ${ }^{28}$

4) Todas estas alteraciones, además, se han producido en un entorno caracterizado por una nueva actitud hacia la globalización y el libre comercio internacional que, en muchos países desarrollados y, también, menos desarrollados, son crecientemente aproximados con hostilidad por amplias capas de la sociedad. Ambas realidades se encuentran sometidas a reevaluación por ciertos gobiernos. Entre ellos, especialmente, por parte de los de algunas naciones desarrolladas que tradicionalmente han apoyado el paradigma del libre comercio y de la libertad de inversiones, y que son parte en un número muy relevante de acuerdos internacionales en la materia a través de los que han coadyuvado a conformar su entendimiento y el marco jurídico sobre el que se sustentan, beneficiándose de ambas realidades

24 Sauvant, Karl P., FDI protectionism is on the rise, policy research working paper 5052, The World Bank poverty reduction and economic management network, International Trade Department World Bank, Washington, 2009, p. 2.

25 UNCTAD, World investment report $2017 \ldots$, op. cit., p. ix.

26 Sauvant, Mascheck \& McAllister, "Foreign direct investment...", op. cit., pp. 3-7.

27 Nótese "China's global 500 companies are bigger than ever —and mostly State-owned_-", Fortune, 22 de julio de 2015, en http:/ / fortune.com/2015/07/22/ china-global-500-government-owned/, consulta del 20 de diciembre de 2017.

28 Lin, Li-Wen \& Milhaupt, Curtis J., "We are the (national) champions: understanding the mechanisms of State capitalism in China", Stanford Law Review, 2013, 65, pp. 699-700. 
durante décadas. ${ }^{29}$ Gobiernos que, en el plano de las inversiones, sin embargo, comienzan a cuestionar seriamente sus consecuencias, tanto en lo relativo a la recepción de flujos inversores directos como a la emisión de estos. ${ }^{30}$

La realidad hoy es que ciertas economías emergentes invierten de forma constante y amplia en los países desarrollados, algunos de los cuales observan con preocupación cómo, gracias al largo proceso de privatización desarrollado por ellos a finales del siglo pasado — apoyado por la crisis económica de los últimos años-, importantes sectores de su economía anteriormente propiedad del Estado, o controlados por este, pertenecen ahora a entidades privadas que gestionan servicios e infraestructuras calificadas en muchas ocasiones como "críticas". ${ }^{31}$ Y que la posibilidad de que estos sectores caigan bajo control extranjero, a través de su adquisición por un inversor foráneo, es real. ${ }^{32}$

Este control extranjero, posible o efectivo, sobre algunos ámbitos de la actividad económica nacional considerados vitales para el Estado y su funcionamiento - como energía, telecomunicaciones, transporte o agua - se entiende en muchas economías receptoras de inversión extranjera que puede tener implicaciones directas y negativas para su seguridad nacional y para la salvaguarda de sus intereses esenciales. ${ }^{33}$

Esta percepción del peligro potencial de las inversiones extranjeras directas favorece la articulación de un discurso de 'securitización' en el ámbito de las inversiones extranjeras, un sector en el que esta dimensión de seguridad estaba presente de manera marginal, e incide directamente en la actitud mantenida por los Estados hacia ellas.

\footnotetext{
29 Algunos consideran que son ellos, en definitiva, los que con su actitud favorecen un "backlash against FDI and trigger a roll-back of investor protection and liberalization" (Sauvant, Karl P., "Driving and countervailing forces: a rebalancing of national FDI policies", Yearbook on International Investment Law \& Policy, 2008-2009, p. 244).

30 Álvarez, José E., “Contemporary foreign investment law: an 'empire of law' or the 'law of empire'?", Alabama Law Review, 2009, 60, pp. 970 y ss.

31 Una noción, la de infraestructuras críticas, que no hace sino ampliarse constantemente (OCDE, Protection of "critical infrastructure" and the role of investment policies relating to national security, OCDE, París, 2008, p. 5).

32 UNCTAD, The protection of national security in ILAs, UNCTAD Series on International Investment Policies for Development, UNCTAD/DIAE/IA/2008/5, UnCTAD, Nueva York-Ginebra, 2009 , p. xv.

33 Ibid., p. xv.
} 


\subsection{Potenciales riesgos generados por las inversiones extranjeras directas}

El debate en torno a las inversiones extranjeras directas ha estado tradicionalmente centrado en sus potenciales beneficios o perjuicios económicos y sociales para el país receptor de estas. Sin embargo, y sin ser este totalmente abandonado, en los últimos tiempos se ha comenzado a incidir, también, en los eventuales riesgos que la inversión extranjera puede entrañar para la seguridad nacional y los intereses esenciales del Estado receptor. Al menos, de cierta inversión proveniente de determinados países o dotada de condición soberana, dirigida a concretos sectores de la economía. ${ }^{34}$

Se habla de esta suerte de, al menos, tres peligros de naturaleza diversa generados por la inversión extranjera directa, esencialmente la canalizada a través de la fusión con, o adquisición de, empresas ya existentes:

1) Se destaca, así, como un potencial primer peligro para la seguridad nacional o para los intereses esenciales de la seguridad del Estado receptor de la inversión, la posibilidad de que el país en que esté radicada la empresa adquirida devenga dependiente de un proveedor de bienes o servicios que se consideran cruciales para el normal funcionamiento del Estado receptor, y que ahora pasa a estar controlado por un inversor extranjero. Y que esta dependencia pueda conllevar retrasos, negativas o imposición de condiciones a la provisión de estos bienes o servicios por parte de la empresa extranjera. ${ }^{35}$

2) La segunda categoría de peligros hace mención a aquellas fusiones y adquisiciones que puedan potencialmente implicar una transferencia de ciertas tecnologías o conocimientos a una entidad controlada por capital extranjero, que podría, posteriormente, ser utilizada por dicha empresa o por un gobierno extranjero de forma contraria a los intereses nacionales del país receptor de la inversión. ${ }^{36}$

34 Esplugues, Carlos, El control de las inversiones extranjeras directas, Tirant lo Blanch, Valencia, 2018, pp. 185-201.

35 Moran, Theodore H., Chinese foreign direct investment in Canada: threat or opportunity?, Canadian Council of Chief Executives-Conseil Canadien des Chiefs d'Enterprise, Ottawa, 2012, pp. 5-6.

36 Ibid., p. 6. 
3) Por último, una tercera categoría de riesgos surge de las fusiones y adquisiciones susceptibles de generar cierta capacidad de infiltración, vigilancia o sabotaje en la prestación de determinados servicios o bienes que se entienden cruciales para el normal funcionamiento de la economía del país receptor de la inversión. ${ }^{37}$

En cualquiera de estos tres supuestos la verificación del eventual peligro se vincula directamente a la disponibilidad del concreto producto, tecnología o práctica involucrada, así como al impacto de la adquisición sobre aquellos que lo pretenden..$^{38} \mathrm{En}$ tal sentido, para que este riesgo sea plausible resulta necesario verificar si existen potenciales proveedores sustitutivos de fácil consecución. Y si, además, lo son en condiciones similares y sin generar elevados costes de sustitución, ${ }^{39}$ tomando en consideración para ello no solo el mercado nacional, sino también el global. ${ }^{40}$

La verificación de la potencialidad de cualquiera de estos riesgos exige, a su vez, la ponderación de una serie de elementos objetivos de distinto calado. Se trata, en suma, de valorar el sector económico al que se dirige la inversión, así como su origen, cuantía o naturaleza. Todos ellos constituyen factores determinantes por considerar a la hora de evaluar el eventual riesgo de la inversión para la seguridad nacional, o los intereses esenciales de la seguridad del Estado receptor de la inversión.

Junto a ellos, además, resulta imprescindible que el objetivo de la inversión resulte 'crítico' para la economía nacional, y para la satisfacción de determinados objetivos esenciales del Estado. $\mathrm{Y}$ en tal sentido, asumiendo estos tres ejemplos de peligro, y dejando de lado el estricto impacto económico, político o social que pueda tener una concreta operación inversora, resultará siempre imprescindible diferenciar entre lo que en sentido estricto constituye auténticos riesgos para la seguridad nacional, el orden público o los intereses esenciales de la seguridad del Estado receptor de la inversión, de lo que son meras excusas para justificar la adopción por parte del Estado de distintas medidas proteccionistas.

\footnotetext{
37 Ibid.

38 Moran, Theodore H., "Foreign acquisitions and national security: what are genuine threats? What are implausible worries?", en Drabek, Zdenek \& Mavroidis, Petros C. (eds.), Regulation of foreign investment challenges to international harmonization, World Studies in International Economics (Vol. 21), Columbia University, Nueva York, 2013, p. 378.

$39 \quad$ Ibid., p. 373.

40 Ibid., pp. 283-285.
} 
En esta línea, la OCDE señaló ya en 2006 que los “[I]ssues of security and other strategic concerns have moved to the forefront of domestic and international investment policy making". ${ }^{41}$ A la vez que alertó, más recientemente, tanto sobre la práctica de un 'bidden protectionism' por parte de algunos Estados, como del abuso de políticas protectoras basadas, entre otros factores, en la protección de la seguridad nacional o factores de similar índole. ${ }^{42}$

\section{El cambio del discurso: una nueva y dispar función para el derecho de las inversiones extranjeras}

Los cambios que han acompañado a la implosión de los flujos inversores durante estas últimas décadas han traído como una de sus consecuencias la adición de una nueva función al régimen jurídico de las inversiones extranjeras. Junto a la tradicional tarea de reglamentar, canalizar o fomentar los flujos inversores, el régimen jurídico de las inversiones extranjeras adquiere ahora una vertiente adicional de control frente a una pluralidad de riesgos, en muchos casos indeterminados y puramente potenciales. Se trata, en última instancia, de preservar la economía y la independencia del país frente a posibles peligros generados por concretos proyectos de inversión extranjera, y de asegurar el normal funcionamiento del Estado y de ciertas infraestructuras críticas, así como su resiliencia.

En coherencia con ello, la regulación de las inversiones pasa a ser una tarea plural que se alcanza a través de una multiplicidad de instrumentos legales presentes en el ordenamiento jurídico del Estado receptor de la inversión, combinando normas estrictamente referidas a las inversiones extrajeras con otras que no fueron en su origen diseñadas para regular esta materia, tales como las normas sobre derecho de la competencia, derecho societario o fusiones y adquisiciones. Normas que ahora son, en muchas ocasiones, reinterpretadas en clave securitaria, atribuyéndoseles un papel relevante en el objetivo de preservar la seguridad nacional y los intereses esenciales del país receptor de la inversión. ${ }^{43}$

\footnotetext{
41 OCDE, International investment perspectives. 2006 edition, OCDE, París, 2006, p. 32.

42 OCDE, Roundtable on freedom of investment 20. 19 March 2014 Summary of roundtable discussions by the OECD Secretariat, OCDE, París, 2014, p. 9.

43 OCDE, Building trust and confidence in international investment. Report by countries participating in the "Freedom of Investment" Process March 2009, OCDE, París, 2009, p. 10.
} 
El resultado directo es que el libre comercio y los flujos inversores dejan de aproximarse exclusivamente desde una perspectiva económica, social o política, viéndose sometidos ahora a una novedosa dimensión de seguridad que, sin tener muy claro su significado último, ni su contenido real en este ámbito, comienza a condicionar en muchos países la aproximación a, y el tratamiento de, la inversión extranjera.

Este nuevo papel atribuido al régimen jurídico de las inversiones foráneas genera el efecto adicional de colocar al marco normativo existente bajo presión, planteando el interrogante de verificar su capacidad efectiva para satisfacer esta función adicional de seguridad que se ve ahora asignada. Hasta el momento, la respuesta ofrecida por parte del Estado respecto de aquellas inversiones extranjeras susceptibles de ser consideradas como potencialmente riesgosas para su seguridad o sus intereses esenciales de la seguridad ha estado muy vinculada al entramado convencional del que es parte y, por lo tanto, se ha focalizado en el momento posterior al desarrollo de la inversión. Sin embargo, las limitaciones intrínsecas que se anudan a esta posición están conduciendo a que, junto a la tradicional respuesta expost, se esté hoy consolidando el diseño de mecanismos ex ante que permitan al Estado receptor evaluar la inversión propuesta y, llegado el caso, condicionarla o incluso bloquearla antes de que se lleve a cabo. ${ }^{44}$

\subsection{La aproximación tradicional: respuesta ex post $\mathrm{y}$ vinculada al entramado convencional existente}

El régimen jurídico internacional de las inversiones extranjeras, muy vinculado — como hemos dicho— a la tupida red de convenios internacionales existente en la materia, se ha focalizado tradicionalmente en el momento posterior a la realización de la inversión. ${ }^{45}$ Escasos son los convenios que abordan conjuntamente la fase previa y posterior de esta. De hecho, tan solo los acuerdos bilaterales concluidos por Estados Unidos y Canadá,

\footnotetext{
44 Ninguna de ambas aproximaciones, empero, impiden al Estado receptor de la inversión prohibir el acceso de la inversión extranjera a ciertos sectores de la economía o con base en ciertos criterios objetivos - Chaisse, Julien, "Promises and pitfalls of the European Union policy on foreign investment. How will the new EU competence on FDI affect the emerging global regime?”, Journal of International Economic Law, 2012, 15, (1), p. 71-.

45 Sornarajah, Muthucumaraswamy, The international law on foreign investment, $3^{\mathrm{a}}$ ed., CuP, Cambridge, 2010, pp. 201-224; Chalamish, Efraim, "Global investment regulation and sovereign funds", Theoretical Inquiries in Law, 2012, 13, (2), p. 668.
} 
y más recientemente por Japón, ${ }^{46}$ y algunos aislados textos multilaterales basados en ellos — como ocurre con el capítulo 11 del NAFTA— ${ }^{47}$ cubren ambas fases. En contra, la mayoría de estos convenios, independientemente de su condición bilateral o multilateral, incluyen esencialmente normas en relación con la promoción y protección de las inversiones extranjeras una vez estas han sido llevadas a la práctica.

El análisis de estos acuerdos refleja la existencia de una creciente tendencia a incluir en ellos cláusulas generales de excepción - O non-precluded measures clauses_-, ${ }^{48}$ que, excepcionando las obligaciones derivadas del convenio que las recoge, amparan la adopción por parte del Estado receptor de determinadas medidas en relación con inversiones ya realizadas. Medidas destinadas a asegurar la preservación de importantes objetivos de orden público, o de decisiones adoptadas con propósitos vinculados a la protección de la salud pública, el medio ambiente o, crecientemente, de la seguridad nacional o los intereses esenciales de su seguridad. ${ }^{49}$

Aun contando con una tipología amplia, un número muy relevante de estas cláusulas reproducen sin más el artículo XXI GATT, ${ }^{50}$ o lo toman

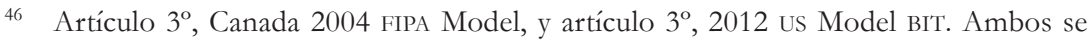
rubrican national treatment. Igualmente, algunos acuerdos de libre comercio concluidos por Estados Unidos también atribuyen este derecho previo a la inversión; ver artículo 10.3 del United States-CAFTA-DR de 2005 o artículo 1102 del NAFTA. Considérese en este sentido Muchlinski, Peter T., "Corporations and the uses of law: international investment arbitration as a 'multilateral legal order", Oñati Socio-Legal Series, 2011, 1, (4), pp. 3-4.

47 En relación con el tratamiento de la fase previa, ver Chaisse, "Promises and pitfalls...", op. cit., p. 72.

48 UNCTAD, The protection of national security..., op. cit., p. 72.

49 Spears, Suzanne A., "The quest for policy space in a new generation of international in-vestment agreements", Journal of International Economic Law, 2010, 13, (4), pp. 1060-1061. Sin embargo, aun siendo creciente y constatable esta tendencia, el número de acuerdos que incluyen este tipo de cláusulas sigue siendo a fecha de hoy limitado en número. Ver Gazzini, Tarcisio, "The role of customary international law in the field of foreign investment", The Journal of World Investment \& Trade, 2017, 10, p. 691.

50 Un precepto que reza así: "No deberá interpretarse ninguna disposición del presente acuerdo en el sentido de que: a) imponga a una parte contratante la obligación de suministrar informaciones cuya divulgación sería, a su juicio, contraria a los intereses esenciales de su seguridad; o b) impida a una parte contratante la adopción de todas las medidas que estime necesarias para la protección de los intereses esenciales de su seguridad, relativas: (i) a las materias fisionables o a aquellas que sirvan para su fabricación; (ii) al tráfico de armas, municiones y material de guerra, y a todo comercio de otros artículos y material destinados directa o indirectamente a asegurar el abastecimiento de las fuerzas armadas; (iii) 
como base directa o indirecta para su redacción. ${ }^{51}$ Esta ligazón entre el tenor del artículo XXI GATT y esta categoría de cláusulas generales de excepción implica, en última instancia, que en su valoración estas se vean concernidas por los variados problemas que, desde su origen, acompañan a la interpretación de este precepto, lo que resulta especialmente relevante a la hora de aproximar la frase "intereses esenciales de su seguridad" recogida en la disposición. ${ }^{52}$

El artículo XXI GATT fue diseñado deliberadamente ambiguo ${ }^{53} \mathrm{y}$, además, ha sido invocado en muy escasas ocasiones. ${ }^{54}$ No se han generado,

a las aplicadas en tiempos de guerra o en caso de grave tensión internacional; o c) impida a una parte contratante la adopción de medidas en cumplimiento de las obligaciones por ella contraídas en virtud de la Carta de las Naciones Unidas para el mantenimiento de la paz y de la seguridad internacionales".

51 No se trata, empero, del único precepto del entramado normativo de la OMC que aborda el tema, pero sí el más relevante y conocido. En paralelo a él, nótense igualmente el artículo XIVbis GATS/AGCS, que cubre las inversiones directas extranjeras de forma limitada - en relación con este precepto ver Cottier, Thomas \& Delimatsis, Panagiotis, "Article XIVbis GATS: security exceptions", en Wolfrum, Rudiger, Stoll, Peter-Tobias \& Feinäugle, Clemens (eds.), Max Planck commentaries on world trade law, WTO-Trade in Services, Vol. 6, Martinus Nijhoff Publishers, Leiden-Boston, 2008, pp. 6 y ss.—; artículo 73 TRIPS/ ADPIC o artículo XXIII:1 APC/GPA o artículo 2.2 TBT/OTC.

52 Nolan, Michael D. \& Sourgens, Frédéric G., "The limits of discretion? Self-judging emergency clauses in international investment agreements", Yearbook on International Investment Law \& Policy, 2010-2011, pp. 365 y 387.

53 "An ambiguity necessitated by the need to allow countries the ability to respond to legitimate security concerns without destroying advances in trade liberalization" (Lindsay, Peter, "The ambiguity of GATT article XXI: subtle success or rampant failure?", Duke Law Journal, 2002-2003, 52, pp. 1310-1311).

54 Existen algunos supuestos en los que ha sido invocado el artículo XXI GATT de forma más o menos explícita: el caso de Checoslovaquia contra Estados Unidos, de 1949, planteado al amparo del artículo XXIII GATT; el caso del boicot por parte de Ghana de productos portugueses, cuando Portugal accedió al GATT en 1961; el caso de Suecia y las cuotas de importación de determinados zapatos, en 1975; el caso de Argentina contra la Comunidad Europea y Australia debido al embargo adoptado como consecuencia de la Guerra de las Malvinas, en 1982; el embargo americano contra Polonia y la URSS en 1982; el supuesto de la República Federal Alemana e Islandia, en 1974; el supuesto de Nicaragua contra Estados Unidos debido al embargo comercial contra Nicaragua, en 1985; el supuesto de las sanciones económicas adoptadas por la Comunidad Europea contra Yugoslavia, en 1991; el caso de la Comunidad Europea contra Estados Unidos debido a la Cuban Liberty and Democratic Solidarity (Libertad) Act, en 1996; el caso de Japón y la Unión Europea contra Estados Unidos debido a la Massachusetts Selective Purchasing Act en 1997; o el caso de Colombia y Honduras contra Nicaragua, en 1999. Ver al respecto, Dattu, Riyaz \& 
por lo tanto, pautas claras en torno a su interpretación y aplicación. Ello se ha traducido, por ejemplo, en el hecho de que, a diferencia de lo que ocurre con el entendimiento atribuible al término "necesarias", que sí ha sido abordado por diversos paneles en el marco del GATT y de la OMC, ${ }^{55}$ no exista una posición jurisprudencial clara en torno al significado de "seguridad" o de "intereses esenciales de su seguridad", 56 a pesar de que la doctrina mayoritariamente apoye una interpretación amplia de estos. ${ }^{57}$

Boscariol, John, "GATT article XXI, Helms-Burton and the continuing abuse of the national security exception”, Canadian Business Law Journal, 1997, 28, pp. 204-205; Vandermeulen, Jackie \& Trebilcock, Michael J., "Canada's policy response to foreign sovereign investment: operationalizing national security exceptions", Canadian Business Law Journal, 2009, 47, p. 421; Piczak, C. Todd, "The Helms-Burton Act: U.S. foreign policy toward Cuba, the national security exception to the GATT and the political question doctrine", University of Pittsburgh Law Review, 1999, 61, pp. 308 y ss.

55 Ver el panel report del 7 de noviembre de 1990 en el caso Thailand-Restrictions on importation of and internal taxes on cigarettes, DS10/R-37S/2009, (en https:/ /www.wto.org/english/ tratop_e/dispu_e/90cigart.pdf, consulta del 26 de noviembre de 2017) que toma como referencia el GATT panel report del 7 de noviembre de 1989 en el asunto United States - Section 337 of the Tariff Act of 1930, L/6439-36S/345 (en https://www.wto.org/gatt_docs/ English/SULPDF/91240197.pdf, consulta del 10 de enero de 2018), y que entendió el término 'necessary' como significando la ausencia de cualquier "alternative measure which (the State) could reasonably be expected to employ and which is not inconsistent with other GATT provisions is available to it. By the same token, in cases where a measure consistent with other GATT provisions is not reasonably available, a contracting party is bound to use, among the measures reasonably available to it, that which entails the least degree of inconsistency with other GATT provisions" (p. 20, par. 74).

56 Bjorklund, Andrea K., "Emergency exceptions", en Muchlinkski, Peter T., Ortino, Federico \& Schreuer, Christoph, The Oxford handbook of international investment law, OUP, Oxford, 2008, pp. 476-485.

57 Burke-White, William W. \& Von Staden, Andreas, "Investment protection in extraordinary times: the interpretation and application of non-precluded measures provisions in bilateral investment treaties", Virginia Journal of International Law, 2008, 48, (2), pp. 351 y ss. Una posición que también es apoyada en alguna ocasión por el Tribunal Internacional de Justicia, que en su sentencia del 27 de junio de 1986 en el asunto Military and paramilitary activities (Nicaragua v. U.S.) explícitamente admite la amplitud del término y su comprensión de riesgos que superan los militares, como riesgos económicos o para la salud pública: “The concept of essential security interests certainly extends beyond the concept of an armed attack, and has been subject to very broad interpretations in the past" ([1986] ICJ 14, p. 107 , par. 224). Pero que, sin embargo, no ha obtenido un apoyo tan claro en la sentencia del propio Tribunal del 12 de diciembre de 1996 en el asunto Oil platforms (Iran v. U.S.) ([1996] ICJ 803, p. 39, par. 73). 
La vaguedad del artículo XXI GATT, y con ello de las cláusulas redactadas con base en él, ${ }^{58}$ abre igualmente el debate en torno a la discrecionalidad, o no, del Estado que se ampara en este tipo de preceptos en relación con la fijación de su contenido. Algo sobre lo que la doctrina está profundamente dividida. ${ }^{59}$ Tampoco los escasos paneles que han abordado esta cuestión en el marco del GATT y de la OMC, ${ }^{60} \mathrm{O}$ la propia jurisprudencia del Tribunal Internacional de Justicia en las ocasiones en que ha tratado este extremo con respecto al artículo XXI GATT, ${ }^{61}$ han aportado una respuesta concluyente al respecto.

Por su parte, la práctica en el ámbito del arbitraje de inversiones reproduce esta inconcluyente situación, combinando de manera mayoritaria la necesaria atención al tenor de la concreta cláusula de excepción sobre la que se articula la decisión adoptada por el Estado receptor de la inversión, ${ }^{62}$ con una posición de partida contraria a la interpretación puramente discrecional de este tipo de cláusulas por el Estado que se ampara en ellas. ${ }^{63}$

58 Que no hayan fijado con nitidez su naturaleza discrecional. Álvarez, José E., "Sovereign concerns and the international investment regime", en Sauvant, Karl P., Sachs, Lisa E. \& Schmit Jongbloed, Wouter P. F. (eds.), Sovereign investment. Concerns and policy reactions, OUP, Oxford, 2012, pp. 273-275.

59 Alford, Roger P., "The self-judging WTO security exception”, Utab Law Review, 2011, 3, pp. 705 y ss.

60 En el ámbito del GATT y de la OMC esta específica cuestión ha sido planteada en los supuestos de Checoslovaquia contra Estados Unidos de 1949, de Nicaragua contra Estados Unidos en 1984 (Nicaragua I), de Nicaragua contra Estados Unidos en 1985-1986 (Nicaragua II) y de Yugoslavia contra la Comunidad Europea en 1991-1992, sin que exista una respuesta clara sobre la cuestión.

${ }_{61}$ Ver el obiter dicta incluido en la sentencia en el asunto Military and paramilitary activities (op. cit., p. 116, par. 222) y que parece aceptar la condición discrecional del precepto. Igualmente, nótese la sentencia del TIJ en el asunto Oilplatforms (Iran v. U.S.), op. cit., p. 183, par. 43 (al respecto, considérese Rose-Ackerman, Susan \& Billa, Benjamin, "Treaties and national security", International Law and Politics, 2008, 40, p. 472). Sin embargo, una postura contraria se encuentra en su decisión del 4 de junio de 2008 en el asunto Certain questions of mutual assistance in criminal matters (Djibouti v. France), [2008] ICJ 177.

62 Laudo del 12 de mayo de 2005 en el asunto CMS Gas Transmission Co. v. Argentine Republic, ICSID Case ARB/01/8, p. 107, par. 370, en http://www.italaw.com/cases/288, consulta del 17 de enero de 2018; y laudo del 22 de mayo de 2007 en el asunto Enron Corporation and Ponderosa Assets, L. P. v. Argentine Republic, ICSID Case ARB/01/3, p. 105, par. 335, en http://www.italaw.com/cases/documents/404, consulta del 22 de enero de 2018.

63 Laudo del 28 de septiembre de 2007 en el asunto Sempra Energy International v. Argentine Republic, ICSID Case ARB/02/16, p. 113, par. 384, en http://www.italaw.com/cases/1002, 
Todo ello coadyuva a agrandar las dudas sobre la viabilidad del sistema de control de las inversiones expost, con vistas a revisar - y en su caso evitar- los flujos de inversiones extranjeras no deseados, por provenir de ciertos países, contar con una naturaleza soberana o dirigirse a sectores determinados de la economía del Estado receptor.

\subsection{Un paso al frente: el control ex ante de las inversiones extranjeras}

\subsubsection{Un cambio de foco y de perspectiva}

Los problemas interpretativos generados por esta tipología de cláusulas no hacen sino agudizar los inconvenientes propios de una respuesta diseñada para hacer frente a inversiones que se entienden perjudiciales para la seguridad nacional o los intereses esenciales de seguridad del Estado receptor de la inversión, tan solo una vez que estas han sido realizadas.

Los drásticos procesos privatizadores, y la crisis económica de la última década, han facilitado que algunas de las más importantes empresas, o áreas de la economía, de ciertas naciones - tanto desarrolladas como menos desarrolladas - se encuentren ahora en manos de inversores extranjeros. Inversores que no siempre proceden de países democráticos o con mercados libres, y en los que no necesariamente juega la idea de reciprocidad. La regulación de las inversiones extranjeras refleja el balance entre los beneficios que el Estado receptor espera recibir de ellas, y los riesgos potenciales que le pueden generar. Y esta ecuación se encuentra hoy cuestionada en muchos lugares, especialmente en algunos países occidentales que parecen encontrarse en pleno proceso de reevaluación de los costes-beneficios de ciertas inversiones foráneas, en el marco de un ambiente de creciente desconfianza hacia ellas.

Ello ha favorecido en los últimos tiempos una focalización en la fase previa a la realización de la inversión. Y se ha traducido en el hecho de que, sin abandonar la vía ex post propia del entramado convencional existente, un número importante de países estén explorando hoy instrumentos para el control y prevención de ciertas operaciones de inversión

consulta del 18 de enero de 2016; y laudo del 22 de mayo de 2007 en el asunto Enron Corporation and Ponderosa Assets, L. P. v. Argentine Republic, op. cit., p. 104, par. 332. 
potencialmente riesgosas para su seguridad nacional o sus intereses esenciales de seguridad, con carácter previo al desarrollo de estas. ${ }^{64}$

Ningún Estado ha mantenido nunca una política de aceptación sin restricciones de las inversiones extranjeras. Siempre se ha impuesto algún tipo de límite. A partir de esta aseveración, y en el marco del incremento sostenido de los flujos globales de inversión extranjeras que ha caracterizado a las últimas décadas, algunos Estados y actores políticos comienzan a plantearse ahora si el enorme entramado convencional en materia de inversiones extranjeras existente no ha supuesto para ellos renunciar a un volumen excesivo de soberanía, restringiendo, por ende, el ejercicio de sus funciones soberanas. Máxime cuando la interpretación de estos acuerdos a través, fundamentalmente del arbitraje, ha favorecido un "regulatory chill" 65 en relación con distintas medidas adoptadas por el legislador nacional, que se entienden imprescindibles para alcanzar ciertos objetivos legítimos del Estado, no solo en el campo estrictamente económico, sino en relación con otros ámbitos diversos, como puedan ser el de la salud, el medio ambiente, los derechos humanos o la propia salvaguarda de la seguridad nacional.

Consecuencia de esta reflexión es el diseño de distintas medidas de naturaleza diversa en cuanto a la entrada, valoración y, en su caso, aprobación de determinadas inversiones extranjeras, cuyo objetivo es defender sus economías frente a lo que el Estado receptor pueda considerar como inversiones poco deseables. ${ }^{66}$ En contraste con el mantra del libre comercio y de la libre circulación de inversiones que ha calificado las últimas décadas, la aceptación de los flujos de inversión extranjera dejaría ahora de ser plena, viniendo calificada, y haciéndose depender de factores tales como el sector o industria objeto de la inversión, el carácter directo o indirecto de esta, su naturaleza puramente privada o soberana, o su origen.

${ }^{64}$ Chaisse, Julien, Chakbaborty, Debashis \& Mukherjee, Jaydeep, "Emerging sovereign wealth funds in the making: assessing the economic feasibility and regulatory strategies", Journal of World Trade, 2011, 45, (4), p. 854.

65 Spears, “The quest for policy space...”, op. cit., pp. 1039-1040.

${ }_{66}$ Götz, Marta, "Pursuing FDI policy in the EU - Member States and their policy space", Journal of Economics and Political Economy, 2015, 2, (2), p. 291. 


\subsubsection{Pluralidad de medidas de control de la inversión ex ante}

Múltiples son las medidas, más clásicas o más novedosas, que se pueden adoptar por un Estado con vistas a controlar aquellas inversiones extranjeras que entiende pueden ser contrarias a su seguridad, a sus intereses esenciales de seguridad o nociones similares. El World Bank's Survey Investing Across Borders in 2010, por ejemplo, destaca cómo una quinta parte de los 87 países analizados en el estudio requieren que las compañías extranjeras superen un proceso de aprobación de la inversión antes de poder llevarla a cabo en ciertos sectores de la economía. Y cerca de un $90 \%$ de ellos restringe la capacidad de las sociedades extranjeras de participar en diversos sectores de la economía nacional, con la presencia de límites más estrictos cuando se trata de servicios. ${ }^{67}$ Adicionalmente, los gobiernos prevén también la posibilidad de sujetar la inversión al cumplimiento de distintas condiciones una vez esta sea llevada a la práctica. ${ }^{68}$

Ello tiende a traducirse en un elenco de medidas susceptibles de ser adoptadas por los distintos Estados, con vistas a controlar la inversión extranjera en ciertas áreas de su economía:

1) La prohibición, total o parcial, de acceso de las inversiones extranjeras en ciertos sectores sensibles de la economía constituye la restricción más obvia de todas las posibles. ${ }^{69}$ Los gobiernos pueden decidir que determinados sectores de su economía, o ciertas empresas consideradas estratégicas por motivos diversos, permanezcan cerrados a la inversión extranjera. La práctica refleja que aquellos sectores más restringidos son los considerados

67 Investment Climate Advisory Services World Bank Group, World Bank's survey investing across borders 2010. Indicators of foreign direct investment regulation in 87 economies, World Bank, Washington, 2010, p. 8.

68 De Meester, Bart, International legal aspects of sovereign wealth funds: reconciling international economic law and the law of State immunities with a new role of the State, Working Paper $\mathrm{N}^{\circ} 20$, Centre for Global Governance Studies Institute for International Law, Lovaina, 2009, pp. 14 y ss.

69 También el número de inversores foráneos admitidos en un sector económico concreto puede verse limitado por el Estado receptor. Ver Kurtz, Jürgen, "A general investment agreement in the WTO? Lessons from chapter 11 of NAFTA and the OECD Multilateral Agreement on Investment", University of Pennsylvania Journal of International Economic Law, 2002, 243, (3), p. 725. 
"highly sensitive to national security or national sovereignty considerations". ${ }^{70}$ En este sentido, los sectores vinculados a la seguridad y al ámbito militar han estado tradicionalmente limitados a la inversión extranjera, aunque se trata, sin embargo, de una realidad cambiante en la que otros, como telecomunicaciones o energía, están adquiriendo un creciente protagonismo. ${ }^{71}$

2) Una segunda medida refiere al mantenimiento de monopolios estatales como forma de preservar frente a la inversión extranjera a algunos sectores de la economía, o empresas, considerados críticos o estratégicos para el Estado. Se trata, de nuevo, de ámbitos particularmente sensibles de la economía nacional, habitualmente vinculados a la provisión de algunos servicios básicos: las telecomunicaciones, el transporte y mantenimiento de infraestructuras, el transporte de petróleo y derivados y gas, las redes eléctricas o la conducción de aguas son ejemplos paradigmáticos de ellos. ${ }^{72}$

3) Una tercera opción alude a las limitaciones de participación empresarial. Ciertos países introducen la exigencia de que la inversión incorpore la participación de socios nacionales, o se canalice a través de joint ventures. O establecen limitaciones de participación o de voto en empresas vinculadas a ciertas áreas de la economía. ${ }^{73} \mathrm{Si}$ bien su eficacia plantea algunas dudas, no deja de tratarse de una de las formas más habituales de control de la inversión foránea. Estas limitaciones se encuentran presentes

70 Golub, Stephen S., Measures of restrictions on inward foreign direct investment for OECD countries, OECD Economic Department Working Paper N 357, OECD Publishing, París, 2003, p. 24.

71 Sothmann, Stephen, "Let he who is without sin cast the first stone: foreign direct investment and national security regulation in China", Indiana International \& Comparative Law Review, 2009, 19, p. 205. En 2008 la OCDE consideró al transporte como el sector en el que existía el mayor número de medidas discriminatorias hacia la inversión extranjera en sus países miembros, seguido de telecomunicaciones y servicio postal, radio y televisión, agricultura y alimentación, agua y tratamientos de agua, y bancos y sector financiero (OCDE, Protection of "critical infrastructure"..., op. cit., pp. 7 y 10-11).

72 UNCTAD, World investment report 2016. Investor nationality: policy challenges, Naciones Unidas, Nueva York-Ginebra, 2016, p. 98.

73 Muchlinski, Peter T., Multinational enterprises \& the law, $2^{\text {a }}$ ed., OuP, Oxford, 2007, pp. 192-201. 
habitualmente en el sector del transporte, bancos y finanzas, recursos naturales y energía, así como telecomunicaciones. ${ }^{74}$ A su vez, en algunos Estados subsiste, igualmente, la presencia de 'acciones de oro' para evitar la adquisición de ciertas sociedades, generalmente antiguas empresas públicas ahora privatizadas, por parte de inversores extranjeros no deseados. ${ }^{75}$

4) Un cuarto nivel de medidas se relaciona con la exigencia de registro obligatorio, y con la imposición de ciertas condiciones de conducta futura. Condiciones generalmente vinculadas a la exigencia de colaboración local, requerimientos de capitalización, objetivos de exportación, participación de capital nacional, o de mano de obra local en su funcionamiento, dirección y gestión, presencia de un número concreto de nacionales o residentes en su consejo de administración, y similares. ${ }^{76}$

5) Sin embargo, la novedad hoy en día en este sector temático estriba en el creciente recurso a mecanismos de verificación de ciertas inversiones extranjeras con base, estrictamente, en su potencial riesgo para la seguridad nacional, los intereses esenciales de seguridad o nociones similares del Estado receptor: los denominados screening systems of evaluation de la inversión extranjera directa. ${ }^{77}$ Se trata de instrumentos acotados en su objetivo que, de base, no suelen mermar el apoyo de los países que los adoptan a la idea de libre circulación de inversiones. Tales mecanismos se articulan sobre criterios diferentes, pero comparten la misma idea de proveer al Estado con un instrumento eficaz para proteger distintas empresas o sectores de la economía de una inversión extranjera que, por sus características, se entiende

74 Graham, Edward M. \& Marchick, David M., U.S. national security and foreign direct investment, Institute for International Economics, Washington, 2006, pp. 13-14.

75 Pollan, Thomas, Legal framework for the admission of FDI, Eleven International Publishing, Utrecht, 2006, pp. 61-62. Esta posibilidad existe, por ejemplo, en el Reino Unido, donde el gobierno cuenta con acciones de oro en BAE Systems, Rolls-Royce o el National Air Traffic Services, habiéndola usado en alguna ocasión.

76 Golub, Measures of restrictions..., op. cit., p. 8; Sornarajah, The international law..., op. cit., pp. $92-115$.

77 Sauvant, Karl P., "Is the United States ready for FDI from China? Overview", en Sauvant, Karl P. (ed.), Investing in the United States is the US ready for FDI from China? Studies in international investment, Edward Elgar, Cheltenham-Northampton, 2009, p. 10. 
que puede generar riesgos para la seguridad nacional o los intereses esenciales de seguridad del país receptor. Incluso la Unión Europea, un espacio especialmente abierto al libre comercio y a la inversión extranjera, se encuentra ahora inmersa en el diseño de un mecanismo de control de las inversiones ${ }^{78}$ destinado a "proteger los activos críticos europeos frente a inversiones que serían perjudiciales para los intereses legítimos de la Unión o de sus Estados miembros". ${ }^{79}$

\section{Los sistemas de evaluación —screening- de inversiones extranjeras con base en su potencial riesgo para la seguridad y los intereses esenciales de seguridad del Estado receptor}

La imposición de limitaciones a la entrada de inversiones extranjeras en un país concreto, incluso cuando se dirige exclusivamente hacia ciertos inversores o grupos de inversores, fue en su día considerada como compatible con las obligaciones derivadas del GATT. En 1984, en el caso de Canada - Administration of the Foreign Investment Act, se avaló el mecanismo canadiense que sometía la aceptación de la inversión extranjera a la obligación del inversor de exportar una cierta cantidad o proporción de su producción. ${ }^{80}$ Estos sistemas se han considerado igualmente compatibles con el derecho internacional. ${ }^{81} \mathrm{E}$, incluso, en un ámbito económico y jurídicamente integrado como es la Unión Europea, este tipo de mecanismos de control de las inversiones extranjeras con base en su potencial riesgo para el "orden público, seguridad y salud públicas" del Estado receptor de la inversión se han entendido acordes con los artículos 63 y 65.3 TFUE,

78 El 13 de septiembre de 2017 se hizo pública la Propuesta de Reglamento del Parlamento Europeo y del Consejo, estableciendo un marco para la evaluación de inversiones extranjeras en la Unión Europea [SWD(2017) 297 final], Bruselas, 13 de septiembre de 2017, $\operatorname{COM}(2017) 487$ final, 2017/0224 (COD), en http://ec.europa.eu/transparency/ regdoc/rep/1/2017/ES/COM-2017-487-F1-ES-MAIN-PART-1.PDF, consulta del 2 de febrero de 2018 (en adelante, Propuesta de Reglamento).

79 Ibid., p. 2.

80 Report of the panel del 7 de febrero de 1984 (L/5504-3 30S/140, pars. 5.18 y 6.2, en https://www.wto.org/english/tratop_e/dispu_e/gatt_e/82fira.pdf, consulta del 4 de febrero de 2018).

81 Sornarajah, The international law..., op. cit., pp. 105-106. 
referentes a la libre circulación de capital y pagos, siempre que satisfagan determinadas condiciones. ${ }^{82}$

La relevancia de esta categoría de mecanismos depende, en última instancia, de las bases sobre las que se articulen y de los objetivos que pretendan, así como de la flexibilidad que acompañe a su aplicación. Los distintos modelos de verificación diseñados toman habitualmente en consideración, entre otros posibles criterios, el sector donde se prevé la inversión, su cuantía o la naturaleza — pública o privada - de esta. ${ }^{83}$

Estos mecanismos suponen el reconocimiento del derecho del Estado a condicionar, o impedir, ciertos proyectos de inversión susceptibles de generarle potenciales problemas de seguridad nacional. ${ }^{84}$ Un reconocimiento que, eso sí, se entiende debe hacerse sin afectar a los derechos y expectativas de los inversores, y asegurando un alto grado de previsibilidad, transparencia y exigibilidad del modelo diseñado. Ello implica, en última instancia, que, en aquellos casos en que alguna medida pueda ser considerada necesaria para salvaguardar la seguridad nacional, el orden público o los intereses esenciales de seguridad del Estado receptor de la inversión, este deberá asegurarse de que las medidas por él adoptadas carecen de carácter discriminatorio y respetan los principios de transparencia, proporcionalidad y responsabilidad..$^{85}$

En el caso concreto de la UE, la compatibilidad con el derecho de la Unión del sistema diseñado se subordina a que las específicas circunstancias requeridas para someter una propuesta inversora a evaluación estén claramente definidas. Y, por lo tanto, ofrezcan al inversor afectado indicaciones con relación a las precisas circunstancias en las que se requiere autorización previa, hasta el punto de permitirle ser consciente de la extensión de sus derechos y obligaciones asegurando, de esta suerte, la virtualidad del principio de seguridad jurídica. ${ }^{86}$ Adicionalmente, cualquier

\footnotetext{
82 STJUE del 14 de marzo de 2000, C-54/99, Eglise de scientologie, ECLI:EU:C:2000:124, par. 13.

83 Clodfelter, Mark A. \& Guerrero, Francesca M. Soria, "National security and foreign government ownership restrictions on foreign investment: predictability for investors at the national level”, en Sauvant, Sachs \& Schmit, Sovereign investment..., op. cit., pp. 175-177. 84 UNCTAD, Investment policy framework for sustainable development, Doc. UNCTAD/DIAE/ РСВ/2015/5, UNCTAD, Ginebra, 2015, p. 8.

85 OECD, Building trust and confidence..., op. cit., p. 5.

86 STJUE del 14 de marzo de 2000, Eglise de scientologie, op. cit., pars. 21 y 22.
} 
persona afectada por una medida restrictiva debe ver reconocida la posibilidad de recurso. ${ }^{87}$

Estas exigencias, sin embargo, chocan con un problema de partida relativo a la concreción del objeto de la protección, y con una práctica caracterizada por su opacidad. La elasticidad de gran parte de las nociones empleadas al conformar estos mecanismos favorece su interpretación maximalista, y crea inevitablemente el riesgo de ocultar ciertos objetivos proteccionistas. ${ }^{88}$ Ahí radica precisamente una de las claves por considerar a la hora de abordar estos esquemas de control. La apuntada distinción entre la necesidad de proteger al Estado frente a inversiones que, como las que afectan a determinadas infraestructuras críticas, pueden incidir en su seguridad nacional. Y la mera promoción de algunas empresas - 'campeones nacionales'-, o la protección de ciertos sectores de la actividad económica o empresas de la competencia de inversores extranjeros. ${ }^{89}$ Una línea que es tenue, y no siempre fácil de trazar.

A partir de esta tensión subyacente, la realidad práctica refleja la presencia de múltiples combinaciones de potenciales sistemas de control, con notables diferencias entre ellos. En ciertos modelos, como el diseñado en Estados Unidos, el mecanismo de evaluación es pensado exclusivamente para proteger de manera global la seguridad nacional del Estado frente a inversiones potencialmente dañinas. En otros casos, por el contrario, el modelo puede combinar requisitos de cantidades o de control y, ocasionalmente, se vinculan al cumplimiento de requerimientos adicionales, como puede ser la exigencia de protección del national interest del país, en Australia; ${ }^{90} \mathrm{o}$ la condición de que la inversión genere beneficio — net benefit - al país receptor, como ocurre en Canadá. ${ }^{91}$

En otros países, como Francia, la aceptación de partida de la libertad de circulación de capitales e inversiones coexiste con la idea de patriotisme économique aplicada para filtrar ciertos proyectos de inversión. El supuesto de Japón es igualmente ilustrativo en este sentido. El artículo 27.3.i.a) y

\footnotetext{
87 Ibid., par.17.

88 Sauvant, FDI protectionism is on the rise..., op. cit., p. 14.

89 Sauvant, Karl P. \& Ortino, Federico, Improving the international investment law and policy regime: options for the future, Ministry for Foreign Affairs of Finland, Helsinki, 2013, p. 38.

90 Cobau, John, "Legal developments in U.S. national security reviews of foreign direct investment (2006-2008)", en Sauvant, Sachs \& Schmit, Sovereign investment..., op. cit., p. 107.

91 Clodfelter \& Guerrero, “National security and foreign...”, op. cit., pp. 178-179.
} 
b) de la Foreign Exchange and Foreign Trade Act permite al Ministro de Finanzas evaluar cualquier inversión extranjera que pueda potencialmente menoscabar la 'seguridad nacional', afectar al mantenimiento del 'orden público', obstaculizar la protección de la 'seguridad pública' o tener un efecto adverso para la buena gestión de la 'economía japonesa'. Ninguno de estos amplios, y vagos, términos viene definido en la ley, y el gobierno se ve atribuido un amplísimo grado de discreción a la hora de ponderar y, en su caso aceptar o condicionar, la inversión propuesta.

Algunos países como Alemania carecen de normas específicas sobre inversión soberana, mientras que este tipo de inversión es sometida a un tratamiento específico en otros Estados como Canadá o Australia. En ciertas naciones, la evaluación de la inversión se desarrolla caso por caso por el propio gobierno —Canadá, Francia o Alemania_, o por la administración —el Foreign Investment Review Board (FIRB), en Australia-, que se ven dotados de amplios poderes con vistas a desarrollar el proceso de ponderación del potencial perjuicio de una inversión para la seguridad nacional del Estado receptor. ${ }^{92}$ Mientras que en otros se atribuyen las tareas de control a una agencia especializada independiente - el Committee on Foreign Investment in the United States (CFIUS) en Estados Unidos-.${ }^{93}$

También los instrumentos jurídicos utilizados para verificar esta compatibilidad varían de país a país. La referencia al derecho de la competencia — China - o a la normativa sobre fusiones y adquisiciones de empresas — Reino Unido - contrasta con el diseño de normativa específica en la materia —Estados Unidos, Alemania, Francia, Australia o Canadá-. Estos sistemas, además, son entendidos en algunos países, y en línea con las propuestas de la OCDE, como un último recurso legal susceptible de ser aplicado, únicamente, cuando no exista otra regulación susceptible de ser utilizada, tal como acontece en Estados Unidos. ${ }^{94}$ Mientras que en

92 Jackson, James K., The Committee on Foreign Investment in the United States (CFIUS), Congressional Research Service, 7-5700, RL33388, Washington, 2015, p. 30.

93 Connell, Paul \& Huang, Tian, "An empirical analysis of CFIUs: examining foreign investment regulation in the United States", The Yale Journal of International Law, 2014, 39, p. 150; Carroll, James F. F., "Back to the future: redefining the foreign investment and national security act's conception of national security”, Emory International Law Review, 2009, 23, pp. 189-197.

$94 \mathrm{La} 2009$ OECD recommendation on guidelines for recipient country investment policies relating to national security apoya explícitamente esta posición. Este tipo de mecanismos debería ser evitado cuando existen otras medidas adecuadas para hacer frente a esta problemática. Ver 
otros Estados la normativa especial diseñada interactúa con otras normas de forma plural. ${ }^{95}$

Junto a la existencia de diferentes objetivos y fundamentos legales en la conformación del modelo de evaluación, también el objeto de protección - la seguridad nacional, los intereses esenciales de seguridad, el orden público...- es aproximado de manera diferente: interpretaciones más estrictas se combinan con aproximaciones más flexibles, o amplias, en los distintos Estados que han introducido estos mecanismos. En todo caso, la mayoría de estos sistemas coinciden en no aportar una definición de los términos de referencia usados en relación con el control de las inversiones extranjeras, limitándose, en ocasiones, a destacar un número de sectores o actividades que pueden plantear potenciales problemas desde la perspectiva de la seguridad nacional, o de los intereses esenciales de seguridad del Estado receptor de la inversión. ${ }^{96}$ A su vez, el contenido y profundidad del procedimiento de evaluación, y el nivel de información requerido al inversor varía notablemente de país a país. ${ }^{97}$

Por último, y no por ello menos relevante, los potenciales riesgos de las inversiones propuestas para la seguridad nacional mudan de Estado a Estado, como lo hacen también los posibles resultados de la evaluación propuesta, aceptándose en ocasiones la posibilidad de prohibiciones parciales, o de aprobaciones sometidas a condiciones presentes o futuras. Así como la posibilidad de recurrir, o no, la decisión adoptada por las autoridades en relación con la inversión propuesta.

\section{5. ¿Cambio de paso o cambio de tendencia?}

La consolidación en el plano comparado de los mecanismos de control de las inversiones extranjeras con base en su potencial riesgo para la seguridad nacional del Estado receptor constituye un síntoma más del momento de cambio que vive el derecho de las inversiones internacionales, en un contexto de creciente cautela hacia ellas. La extensión de su diseño, y uso,

\footnotetext{
OCDE, Recommendation of the Council on guidelines for recipient country investment policies relating to national security C (2009)63, OECD, París, 2009, annex 3.

95 Salacuse, Jeswald, The three laws of international investment. National, contractual and international frameworks for foreign capital, OUP, Oxford, 2013, pp. 121-122.

96 UNCTAD, World investment report 2016 ..., op. cit., pp. 94-5.

97 Ibid., pp. 99-100.
} 
en un entorno económico y geoestratégico muy variable, abre el debate sobre la finalidad real de este sector del derecho, a la vez que plantea dudas lógicas, y relevantes, con respecto a los términos futuros de su utilización, y a su incidencia sobre la libre circulación de inversiones.

Hasta el momento el paradigma de la bondad de la libre circulación de las inversiones extranjeras no se ha visto afectado de manera significativa por la presencia de estos mecanismos. Tampoco los flujos de inversión globales parecen haberse resentido. Sin embargo, la consolidación del uso de instrumentos de control de las inversiones de carácter nacional, con base en nociones genéricas y vagas como las de seguridad nacional, intereses esenciales de seguridad o similares, susceptibles de obtener diferentes interpretaciones en lugares y momentos diversos, favorece una cierta inseguridad jurídica y lanza un mensaje que previsiblemente acabará afectándole.

El impacto dependerá, en última instancia, de factores tales como hasta qué punto sean capaces los Estados de limitar el uso de estos mecanismos a los estrictos objetivos de salvaguarda de la seguridad nacional, renunciando a convertirlos en vías encubiertas de limitación de las inversiones extranjeras por razones comerciales o económicas. Y en esta tarea, la ausencia de un marco normativo uniforme en materia de inversiones extranjeras no constituye un elemento positivo.

\section{Referencias}

Alford, Roger P., "The self-judging WTO security exception", Utah Law Review, 2011, 3, pp. 697-759.

Álvarez, José E., "Contemporary foreign investment law: an 'empire of law' or the 'law of empire’?", Alabama Law Review, 2009, 60, pp. 943-975.

Álvarez, José E., "Sovereign concerns and the international investment regime", en Sauvant, Karl P., Sachs, Lisa E. \& Schmit Jongbloed, Wouter P. F. (eds.), Sovereign investment. Concerns and policy reactions, Oup, Oxford, 2012, pp. 258-282.

Bitzenis, Aristidis, "Globalization and foreign direct investment", en Bitzenis, Aristidis, Vlachos, Vasileios A. \& Papadimitriou, Pyrros. (eds.), Mergers and acquisitions as the pillar of foreign direct investment, Palgrave McMillan, Nueva York, 2012, pp. 9-24.

Bjorklund, Andrea K., "Emergency exceptions", en Muchlinkski, Peter T., Ortino, Federico \& Schreuer, Christoph, The Oxford handbook of international investment law, OUP, Oxford, 2008, pp. 459-523. 
Broude, Tomer, "Investment and trade: the 'Lottie and Lisa' of international economic law?”, en Echandi, Roberto \& Sauvé, Pierre, Prospects in international investment law and policy World Trade Forum, CuP, Cambridge, 2013, pp. 139-155.

Burke-White, William W. \& Von Staden, Andreas, "Investment protection in extraordinary times: the interpretation and application of nonprecluded measures provisions in bilateral investment treaties", Virginia Journal of International Law, 2008, 48, (2), pp. 307-410.

Carroll, James F. F., "Back to the future: redefining the foreign investment and national security act's conception of national security", Emory International Law Review, 2009, 23, pp. 167-200.

Chaisse, Julien, "Promises and pitfalls of the European Union policy on foreign investment. How will the new EU competence on FDI affect the emerging global regime?", Journal of International Economic Law, 2012, 15, (1), pp. 51-84.

Chaisse, Julien, Chakbaborty, Debashis y Mukherjee, Jaydeep, "Emerging sovereign wealth funds in the making: assessing the economic feasibility and regulatory strategies", Journal of World Trade, 2011, 45, (4), pp. 837-875.

Chalamish, Efraim, "Global investment regulation and sovereign funds", Theoretical Inquiries in Law, 2012, 13, (2), pp. 645-681.

Clodfelter, Mark A. \& Guerrero, Francesca M. Soria, "National security and foreign government ownership restrictions on foreign investment: predictability for investors at the national level", en Sauvant, Karl P., Sachs, Lisa E. \& Schmit Jongbloed, Wouter P. F. (eds.), Sovereign investment. Concerns and policy reactions, OuP, Oxford, 2012, pp. 173-220.

Cobau, John, "Legal developments in U.S. national security reviews of foreign direct investment (2006-2008)", en Sauvant, Karl P., Sachs, Lisa E. \& Schmit Jongbloed, Wouter P. F. (eds.), Sovereign investment. Concerns and policy reactions, Oup, Oxford, 2012, pp. 104-119.

Connell, Paul \& Huang, Tian, "An empirical analysis of CFIUs: examining foreign investment regulation in the United States", The Yale Journal of International Law, 2014, 39, pp. 131-163.

Cottier, Thomas \& Delimatsis, Panagiotis, "Article XIVbis GATS: security exceptions", en Wolfrum, Rudiger, Stoll, Peter-Tobias y Feinäugle, Clemens (eds.), Max Planck commentaries on world trade law, WTO - Trade in services, Vol. 6, Martinus Nijhoff Publishers, Leiden-Boston, 2008. 
Dattu, Riyaz \& Boscariol, John, "GATT article XXI, Helms-Burton and the continuing abuse of the national security exception", Canadian Business Law Journal, 1997, 28, pp. 198-209.

De Brabandere, Eric, "Arbitral decisions as a source of international investment law", en Gazzini, Tarcisio y De Brabandere, Eric (eds.), International investment law. The sources of rights and obligations, Martinus Nijhoff Publishers, Leiden-Boston, 2012, pp. 245-288.

De Meester, Bart, International legal aspects of sovereign wealth funds: reconciling international economic law and the law of state immunities with a new role of the State, Working Paper No 20, Centre for Global Governance Studies Institute for International Law, Lovaina, 2009.

Economou, Persephone \& Sauvant, Karl P., "Recent trends and issues in foreign direct investment 2010", Yearbook on International Investment Law \&o Policy, 2010-2011, pp. 3-36.

Esplugues, Carlos, El control de las inversiones extranjeras directas, Tirant lo Blanch, Valencia, 2018.

Esplugues, Carlos, Foreign investment, strategic assets and national security, Intersentia, Cambridge, 2018.

Gazzini, Tarcisio, "The role of customary international law in the field of foreign investment", The Journal of World Investment \& Trade, 2017, 10, pp. 691-715.

Geiger, Rainer, "Towards a multilateral agreement on investment", Cornell International Law Journal, 1998, 31, pp. 467-475.

Golub, Stephen S., Measures of restrictions on inward foreign direct investment for OECD countries, OECD Economic Department Working Paper $\mathrm{N}^{\mathrm{o}}$ 357, OECD Publishing, París, 2003.

Götz, Marta, "Pursuing FDI policy in the EU - Member States and their policy space", Journal of Economics and Political Economy, 2015, 2, (2), pp. 290-308.

Graham, Edward M. \& Marchick, David M., U.S. national security and foreign direct investment, Institute for International Economics, Washington, 2006.

Jackson, James K., The Committee on Foreign Investment in the United States (CFIUS), Congressional Research Service, 7-5700, RL33388, Washington, 2015.

Juillard, Patrick, "L'evolution des sources du droit des investissements", Recueil des Cours, 1994, (1), pp. 1-250.

Kläger, Roland, Fair and equitable treatment' in international investment law, CuP, Cambridge, 2011. 
Kurtz, Jürgen, "A general investment agreement in the WTO? Lessons from chapter 11 of NAFTA and the OECD multilateral agreement on investment", University of Pennsylvania Journal of International Economic Law, 2002, 243, (3), pp. 713-789.

Lin, Li-Wen \& Milhaupt, Curtis J., "We are the (national) champions: understanding the mechanisms of State capitalism in China", Stanford Law Review, 2013, 65, pp. 697-759.

Lindsay, Peter, "The ambiguity of GATT article XXI: subtle success or rampant failure?”, Duke Law Journal, 2002-2003, 52, pp. 1277-1313.

Lorz, Ralph Alexander, "Fragmentation, consolidation and the future relationship between international investment law and general international law", en Baetens, Freya (ed.), Investment law within international law. Integrationist perspectives, CUP, Cambridge, 2013, pp. 483-493.

Moran, Theodore H., "Foreign acquisitions and national security: what are genuine threats? What are implausible worries?", en Drabek, Zdenek \& Mavroidis, Petros C. (eds.), Regulation of foreign investment challenges to international harmonization, World Studies in International Economics (Vol. 21), Columbia University, Nueva York, 2013, pp. 371-393.

Moran, Theodore H., Chinese foreign direct investment in Canada: threat or opportunity?, Canadian Council of Chief Executives-Conseil Canadien des Chiefs d'Enterprise, Ottawa, 2012.

Muchlinski, Peter T., "Corporations and the uses of law: international investment arbitration as a 'multilateral legal order", Oñati Socio-Legal Series, 2011, 1, (4), pp. 3-25.

Muchlinski, Peter T., "Towards a coherent international investment system: key issues in the reform of international investment law", en Echandi, Roberto \& Sauvé, Pierre, Prospects in international investment law and policy World Trade Forum, CuP, Cambridge, 2013, pp. 411-442.

Muchlinski, Peter T., Multinational enterprises \& the law, $2^{\mathrm{a}}$ ed., OuP, Oxford, 2007.

Nolan, Michael D. \& Sourgens, Frédéric G., "The limits of discretion? Self-judging emergency clauses in international investment agreements", Yearbook on International Investment Law \& Policy, 2010-2011, pp. 363-418.

Páez, Laura, Liberalizing financial services and foreign direct investment. Developing a framework, for commercial banking FDI, Palgrave McMillan, Nueva York, 2011. 
Pauwelyn, Joost, "Rational design or accidental evolution? The emergence of international investment law", en Douglas, Zachary, Pauwelyn, Joost \& Viñuales, Jorge E. (eds.), The foundations of international investment law bringing theory into practice, OUP, Oxford, 2014, pp. 11-43.

Piczak, C. Todd, “The Helms-Burton Act: U.S. foreign policy toward Cuba, the national security exception to the GATT and the political question doctrine", University of Pittsburgh Law Review, 1999, 61, pp. 287-327.

Pollan, Thomas, Legal framework for the admission of FDI, Eleven International Publishing, Utrecht, 2006.

Rose-Ackerman, Susan \& Billa, Benjamin, "Treaties and national security", International Law and Politics, 2008, 40, pp. 437-496.

Salacuse, Jeswald, The three laws of international investment. National, contractual and international frameworks for foreign capital, OUP, Oxford, 2013.

Sauvant, Karl P. \& Ortino, Federico, Improving the international investment law and policy regime: options for the future, Ministry for Foreign Affairs of Finland, Helsinki, 2013.

Sauvant, Karl P., "Driving and countervailing forces: a rebalancing of national FDI policies", Yearbook on International Investment Law \& Policy, 2008-2009, pp. 215-272.

Sauvant, Karl P., "Is the United States ready for FDI from China? Overview", en Sauvant, Karl P. (ed.), Investing in the United States is the US ready for FDI from China? Studies in international investment, Edward Elgar, Cheltenham-Northampton, 2009, pp. 1-21.

Sauvant, Karl P., "The regulatory framework for investment: where are we headed?", en Ramamurti, R. \& Nashai, N. (eds.), The future of foreign direct investment and the multinational enterprise, Emerald Books, Research in Global Strategic Management, Vol. 15, Bingley, 2011, pp. 407-433.

Sauvant, Karl P., FDI protectionism is on the rise, policy research working paper 5052, The World Bank poverty reduction and economic management network, International Trade Department World Bank, Washington, 2009.

Sauvant, Karl P., Mascheck, Wolfgang A. \& McAllister, Geraldine, "Foreign direct investment by emerging market multinational enterprise the impact of the financial crisis and recession, and challenges ahead", en Sauvant, Karl P., McAllister, Geraldine \& Macheck, Wolfgang A., Foreign direct investments from emerging markets. The challenges ahead, Palgrave Macmillan Us, Nueva York, 2010.

Sauvé, Pierre, "Multilateral rules on investment: is forward movement possible?", Journal of International Economic Law, 2006, 9, (2), pp. 325-355. 
Sornarajah, Muthucumaraswamy, The international law on foreign investment, $3^{\mathrm{a}}$ ed., Cup, Cambridge, 2010.

Sothmann, Stephen, "Let he who is without sin cast the first stone: foreign direct investment and national security regulation in China", Indiana International \& Comparative Law Review, 2009, 19, pp. 203-231.

Spears, Suzanne A., "The quest for policy space in a new generation of international investment agreements", Journal of International Economic Law, 2010, 13, (4), pp. 1037-1076.

Steger, Debra P., "International trade and investment: towards a common regime?", en Echandi, Roberto \& Sauvé, Pierre, Prospects in international investment law and policy World Trade Forum, CUP, Cambridge, 2013, pp. 156-165.

Thomsen, Stephen \& Mistura, Fernando, Is investment protectionism on the rise? Evidence from the OECD FDI Regulatory Restrictiveness Index' OECD global forum on international investment, OCDE, París, 2017.

Vandermeulen, Jackie \& Trebilcock, Michael J., “Canada’s policy response to foreign sovereign investment: operationalizing national security exceptions", Canadian Business Law Journal, 2009, 47, pp. 392-434.

Vandevelde, Kenneth J., "A brief history of international investment agreements", en Sauvant, Karl P. \& Sachs, Lisa E., The effect of treaties on foreign direct investment: bilateral investment treaties, double taxation treaties, and investment flows, Oup, Oxford, 2009, pp. 3-35.

\section{Documentos oficiales}

Investment Climate Advisory Services World Bank Group, World Bank's survey investing across borders 2010. Indicators of foreign direct investment regulation in 87 economies, World Bank, Washington, 2010.

OCDE, Building trust and confidence in international investment. Report by countries participating in the "Freedom of Investment" Process March 2009, OCDE, París, 2009.

OCDE, Freedom of investment, national security and 'strategic' industries. Progress report by the OECD Investment Committee, OCDE, París, 2008.

OCDE, International investment perspectives. 2006 edition, OCDE, París, 2006.

OCDE, Protection of "critical infrastructure" and the role of investment policies relating to national security, OCDE, París, 2008.

OCDE, Recommendation of the Council on guidelines for recipient country investment policies relating to national security C (2009)63, OECD, París, 2009. 
OCDE, Roundtable on freedom of investment 20. 19 March 2014 Summary of roundtable discussions by the OECD Secretariat, OCDE, París, 2014.

UNCTAD, "Global FDI flows slip in 2016. Modest recovery expected in 2017”, Global Investment Trends Monitor, 2017, 25.

UNCTAD, Investment policy framework for sustainable development, Doc. UNCTAD/ DIAE/PCB/2015/5, UNCTAD, Ginebra, 2015.

UNCTAD, The protection of national security in ILAs, UNCTAD Series on International Investment Policies for Development, UNCTAD/DIAE/ IA/2008/5, UNCTAD, Nueva York-Ginebra, 2009.

UNCTAD, World investment report 2015. Reforming international investment governance, Naciones Unidas, Nueva York-Ginebra, 2015.

UNCTAD, World investment report 2016. Investor nationality: policy challenges, $\mathrm{Na}$ ciones Unidas, Nueva York-Ginebra, 2016.

UNCTAD, World investment report 2017. Investment and the digital economy, Naciones Unidas, Nueva York-Ginebra, 2017.

\section{Jurisprudencia del Tribunal Internacional de Justicia}

Barcelona Traction, Light and Power Company, Limited (Belgium v. Spain), [1970] ICJ 1.

Certain questions of mutual assistance in criminal matters (Djibouti v. France), [2008] ICJ 177.

Military and paramilitary activities (Nicaragua v. U.S.), [1986] ICJ 14.

Oil platforms (Iran v. U.S.), [1996] ICJ 803.

\section{Jurisprudencia del Tribunal de Justicia de la Unión Europea}

STJUE del 14 de marzo de 2000, C-54/99, Eglise de scientologie, ECLI:EU:C:2000:124.

\section{Laudos arbitrales}

AWG Group Ltd. v. The Argentine Republic, Uncitral, Decisión sobre responsabilidad del 30 de julio de 2010, en http://www.italaw.com/ sites/default/files/case-documents/ita0055.pdf, consulta del 2 de febrero de 2018.

CMs Gas Transmission Co. v. Argentine Republic, ICSID Case ARB/01/8, laudo del 12 de mayo de 2005, en http://www.italaw.com/cases/288, consulta del 17 de enero de 2018 . 
Enron Corporation and Ponderosa Assets, L. P. v. Argentine Republic, ICSID Case ARB/01/3, laudo del 22 de mayo de 2007, en http://www.italaw. $\mathrm{com} /$ cases/documents/404, consulta del 22 de enero de 2018.

Mondev International Ltd. v. United States of America, ICSID Case ARB(AF)/99/2, laudo del 11 de octubre de 2002, en http:/ /www.italaw.com/cases/ documents/716, consulta del $1^{\circ}$ de febrero de 2018.

Sempra Energy International v. Argentine Republic, ICSID Case ARB/02/16, laudo del 28 de septiembre de 2007, en http://www.italaw.com/ cases/1002, consulta del 18 de enero de 2016.

\section{Órgano de Resolución de Diferencias de la OMc/GATT}

Canada - Administration of the Foreign Investment Act, L/5504-3 30S/140, pars. 5.18 y 6.2, panel report del 7 de febrero de 1984, en https://www. wto.org/english/tratop_e/dispu_e/gatt_e/82fira.pdf, consulta del 4 de febrero de 2018.

Thailand - Restrictions on importation of and internal taxes on cigarettes, DS10/R37S/2009, panel report del 7 de noviembre de 1990, en https:/ /www. wto.org/english/tratop_e/dispu_e/90cigart.pdf, consulta del 26 de noviembre de 2017.

United States - Section 337 of the Tariff Act of 1930, L/6439-36S/345, panel report del 7 de noviembre de 1989, en https://www.wto.org/ gatt_docs/English/SULPDF/91240197.pdf, consulta del 10 de enero de 2018.

\section{Recursos electrónicos}

"China's global 500 companies are bigger than ever — and mostly State-owned-", Fortune, 22 de julio de 2015, en http://fortune. com/2015/07/22/china-global-500-government-owned/, consulta del 20 de diciembre de 2017. 